\title{
Editorial
}

\section{Quality of Life Research in Otorhinolaryngology}

Traditional concepts in medicine frequently consider the physical conditions of the patient as the sole subject of diagnostics and therapy. In many cases the impact of emotional or social factors on characteristics and course of the disease are underestimated.

The World Health Organization (WHO) defines health as a state of complete physical, mental and social well-being and not merely the absence of disease or infirmity [1]. On the basis of this definition a multidimensional construct was developed including mental and social dimensions into the assessment of health-related quality of life (QOL).

QOL research started in the field of oncology. However, since the nineties more and more QOL measures for non-oncologic otorhinolaryngological diseases were developed. Examples for that are the Sino-Nasal Outcome Test 20 (SNOT-20) for application in patients with chronic rhinosinusitis, the Chronic Ear Survey (CES) for use in patients with chronic otitis media, or the Voice Handicap Index (VHI) which allows QOL assessment of dysphonic patients [2-4].

In this special issue we focus on different health conditions in otorhinolaryngology. The articles by Baumann and Skevas et al. deal with very common ENT diseases (chronic rhinosinusitis, chronic tonsillitis) which are of great medical and economic importance in daily practice [5,6]. A large number of publications have been published on these topics over the last fifteen years and were analyzed in writing the reviews. Christoph Löffler et al. give a nice overview on QOL in Cochlear Implant patients which has increasingly been investigated over the past years [7]. Another paper by Holderried et al. updates information on QOL in patients with hereditary hemorrhagic teleangiectasia (HHT) [8]. Furthermore, Sertel et al. give an overview on QOL measurements in patients treated with Traditional Chinese Medicine (TCM) [9].

This special issue of TOORLJ does not have the intention to cover all aspects of QOL research in otorhinolaryngology. However, it gives an introduction into this important and prospering field of research which nowadays deals with common as well as rare diseases in otolaryngology.

\section{REFERENCES}

[1] World Health Organization. The economics of health and disease. WHO Chron 1970; 25: 20-4.

[2] Jacobson BH, Johnson A, Grywalski C, et al. The voice handicap index (VHI): development and validation. Am J Speech Lang Pathol 1997; 6: 66.

[3] Nadol JB Jr, Staecker H, Gliklich RE. Outcomes assessment for chronic otitis media: the chronic ear survey. Laryngoscope 2000; 110: 32-5.

[4] Piccirillo JF, Merritt MG Jr, Richards ML. Psychometric and clinimetric validity of the 20-Item Sino-Nasal Outcome Test (SNOT-20). Otolaryngol Head Neck Surg 2002; 126: 41-7.

[5] Baumann I. Subjective outcomes assessment in chronic rhinosinusitis. Open Otorhinolaryngol J 2010; 4 : 28-33.

[6] Skevas T, Plinkert PK, Baumann I. Measuring quality of life in adult patients with chronic tonsillitis. Open Otorhinolaryngol J 2010; 4: 34-46.

[7] Loeffler C, Aschendorff A, Burger T, Kroeger S, Laszig R, Arndt S. Quality of life measurements after cochlear implantation. Open Otorhinolaryngol J 2010; 4: 47-54.

[8] Holderried M, Baur M, Pfister M. Impact of hereditary hemorrhagic teleangiectasia on quality of life. Open Otorhinolaryngol J 2010; 4: 55-61.

[9] Sertel S, Greten HJ, Kraemer HJ, Efferth T, Plinkert PK, Baumann I. Evaluation of quality of life in patients treated with traditional Chinese medicine. Open Otorhinoplaryngol J 2010; 4: 62-7.

(C) Ingo Baumann; Licensee Bentham Open

This is an open access article licensed under the terms of the Creative Commons Attribution Non-Commercial License (http: //creativecommons.org/licenses/by$\mathrm{nc} / 3.0 /$ ) which permits unrestricted, non-commercial use, distribution and reproduction in any medium, provided the work is properly cited. 